\title{
Jogo dos Erros: motivos pelos quais um artigo é aceito ou rejeitado pelos periódicos científicos
}

\author{
Game of Errors: Reasons why a paper is accepted or rejected for \\ publication by scientific journals
}

\author{
Anselmo Gomes de OLIVEIRA; \\ Dâmaris SILVEIRA \\ Editores-Chefe
}

Receber de um editor a informação de que seu artigo submetido, embora apresente mérito, não será publicado; ou, simplesmente, ter seu texto rejeitado pelo periódico a que foi submetido, não é uma questão de fácil aceitação. A dúvida mais frequente é "Onde foi que errei?". Em setembro de 2012, Peter Thrower, Editor-chefe da revista Carbon, periódico da American Carbon Society, publicado pela Editora Elsevier, revelou os oito principais motivos pelos quais muitos manuscritos nem chegavam ao processo de revisão pelos pares, ou seja, eram rejeitados pelo próprio editor (1). Em janeiro do ano seguinte, Elisabeth Zwaaf solicitou a 5 Editores de revistas da Elsevier que revelassem os principais motivos pelos quais um manuscrito é publicado (2). Essas são questões importantes que permeiam a comunidade científica. A sensação de "frustração", "injustiça", "desânimo" já acometeu, ao menos uma vez, a qualquer pesquisador que publica seus resultados, independente se está no início da vida acadêmica ou se tem uma carreira científica consolidada.

Em Infarma - Ciências Farmacêuticas, a taxa de rejeição de manuscritos, em 2016, foi de 71\%. E em 2017, até setembro, $80 \%$ dos manuscritos em avaliação foram rejeitados. Dessa forma, aqui serão abordadas algumas das principais questões envolvidas no processo - da submissão até a publicação de um artigo - mas que se aplicam a qualquer periódico que atue com princípios de análise claros e suficientemente éticos. Conhecer o processo pode evitar uma série de equívocos que inviabilizam a publicação do artigo, mesmo que os resultados sejam interessantes e relevantes.

Antes de tudo, é importante entender qual a é responsabilidade do Editor no fluxo de avaliação global do artigo. Ao Editor cabe o desenvolvimento e a manutenção da reputação do periódico, principalmente daqueles cuja publicação está ligada a Instituições Profissionais, como o caso de Infarma - Ciências Farmacêuticas, vinculado ao Conselho Federal de Farmácia. Também é de responsabilidade do Editor todo o conteúdo de assuntos publicados em cada número disponível. O Editor deve ter a perspicácia de identificar se o texto submetido encontra-se dentro do escopo da revista, ou se representa algum assunto ou área emergente que mereça ampliação no elenco de assuntos tratados pelo periódico. Contudo, antes de entrar no mérito dos artigos, existem alguns aspectos primordiais para que o Editor possa ser atraído pelo texto e ser convencido a encaminhar o manuscrito para os assessores ad hoc.

Todos os periódicos organizados têm muito claras, em seus sites de submissão on line, as instruções para os autores que, além de informar sobre o processo de submissão e avaliação dos artigos, orientam, detalhadamente, como os artigos devem ser apresentados em termos de construção do texto e formatação. Assim, ler as instruções e seguir cuidadosamente as orientações é o primeiro passo na submissão adequada. Se o manuscrito não atende minimamente aos requisitos do periódico quanto à formatação do texto, das referências, das figuras e tabelas, torna difícil, para o Editor, avaliar o mérito do conteúdo do texto. Além disso, um artigo científico pressupõe a utilização de linguagem científica, a qual tem características próprias que a distinguem da linguagem que usamos no dia a dia. Um manuscrito que não prima pela linguagem científica e apresenta equívocos gramaticais e de estilo, certamente estará em grande desvantagem em relação a outro manuscrito que atenda a esses requisitos. Nessa categoria podem ser incluídos o texto incompleto, com metodologia descrita de forma insuficiente, a ausência da afiliação dos autores, palavras chaves ou referências. 
O escopo da revista é outro aspecto importante, pois define os assuntos que são de interesse para um público especifico. Em Infarma - Ciências Farmacêuticas o escopo é bastante amplo e compreende toda a área das Ciências Farmacêuticas. Por esse motivo, é pouco provável que um artigo seja rejeitado por não atender ao escopo. Contudo, é bom ressaltar que não basta que o assunto seja de interesse da grande área, mas sim que aquilo que esteja sendo tratado traga alguma nova contribuição no campo específico da pesquisa. Dessa forma, certificar-se de que a submissão atende a esses requisitos iniciais garante que, no mínimo, seja o manuscrito encaminhado aos assessores ad hoc.

A avaliação ad hoc representa a opinião de especialistas nos respectivos assuntos, e constituem a interface entre o editor e os autores. São esses revisores que transmitirão ao Editor as informações essenciais para a tomada de decisão em última instância, ou seja, se o artigo poderá ser publicado ou se deverá ser rejeitado. A responsabilidade do assessor ad hoc é avaliar o mérito do assunto contido no manuscrito, a ocorrência de plágio e a novidade de tema.

Com relação ao mérito do artigo propriamente dito, cabem algumas observações específicas. O delineamento do estudo é um aspecto primordial; e nem um artigo bem escrito, consegue mascarar um erro na concepção do estudo. Neste contexto, podem ser incluídas a apresentação e a justificativa do assunto na introdução, a coerência entre a metodologia, os resultados apresentados e a conclusão. Também é considerado se há coerência entre as referências bibliográficas, as afirmações e a significância dos resultados. Manuscritos que representem informações de estudos parciais e não de um trabalho completo; nos quais os resultados são discutidos em relação a um trabalho, ignorando outros estudos importantes; que representem estudo incremental, mas de interesse insignificante no campo da pesquisa, têm grande chance de serem rejeitados ou de os avaliadores solicitarem uma revisão extensa.
Quanto aos resultados, a forma pela qual são apresentados pode influenciar, favoravelmente ou não, os editores e revisores. Eles devem ser descritos de forma clara e detalhada e não podem ser confundidos com interpretações de dados ou com a discussão, embora possam apresentados conjuntamente.

A falta de originalidade ou novidade científica também são questões extremamente importantes na decisão dos editores. Por exemplo, a preparação de um medicamento contendo um fármaco de administração oral, por meio de metodologia convencional, com tecnologia e excipientes conhecidos nada acrescenta aos conhecimentos atuais, anulando o valor científico do texto (3).

A literatura mostra que os principais motivos de rejeição dos artigos pelos periódicos são a falta de avanço no campo da pesquisa e relevância do tema (27\%), problemas na redação $(26 \%)$, problemas na estruturação do estudo (17\%), descrição da metodologia (13\%) e interpretação de resultados (8\%) (4). Infarma - Ciências Farmacêuticas, por princípio, concede aos autores várias oportunidades de revisar e melhorar o manuscrito. Considerando que muitos dos autores que submetem seus manuscritos à avaliação por Infarma - Ciências Farmacêuticas são jovens, com pouca experiência em publicação de artigos científicos, raras são as ocasiões nas quais um manuscrito é rejeitado na primeira avaliação (pelo Editor), mesmo que cerca de $70 \%$ dos manuscritos recebidos mostrem, claramente, que as orientações para a submissão não foram adequadamente seguidas. Usualmente, manuscritos passam por três ou quatro rodadas de avaliação.

Finalmente, independentemente das razões para aceitação ou para rejeição, se os autores conseguirem evitar os mais simples aspectos desmerecedores do texto, certamente terão chances reais de que seu artigo possa ser aceito em periódicos científicos respeitáveis em quaisquer áreas de conhecimento.

\section{REFERÊNCIAS}

1. Thrower P. Eight reasons I rejected your article. Elsevier Connect (https://wwwelseviercom/connect/8-reasons-i-rejected-your-article) 2012.

2. Zwaaf E. 8 reasons I accepted your article. Elsevier Connect (https://wwwelseviercom/connect/8-reasons-i-accepted-your-article)2013.
3. Ali J. Manuscript rejection: Causes and remedies. J Young Pharm. 2010;2(1):3-6. DOI: 10.4103/0975-1483. 62205

4. Gongal P. Why research papers are rejected (http://www. theenglishedition.com/wordpress/?p=138): The Monologue; 2013 [cited 2017]. 